\section{Nuevas pistas para mejorar la vacuna antituberculosa}

Cuando a principios del siglo XX Calmette y Guérin elaboraron la primera vacuna contra la tuberculosis, conocida por vacuna BCG (por bacilo de Calmette y Guérin), los investigadores hicieron uso de una cepa viva pero atenuada de Mycobacterium bovis lograda a base de la supresión de varios genes que determinan la virulencia y que se sitúan en la llamada región de deleción [RD] 1. Aplicada en el momento de nacer o poco tiempo después, esta vacuna es capaz de reducir notablemente la incidencia de ciertas formas de tuberculosis propias de la infancia, pero tiene poco efecto en la incidencia de la enfermedad pulmonar en personas adultas, la cual explica casi toda la epidemia actual en zonas endémicas. Si se tiene en cuenta que la tuberculosis ocasiona alrededor de 2 millones de defunciones anuales, hay una necesidad urgente de mejorar la eficacia de la vacuna.

Uno de los genes de Mycobacterium tuberculosis que se suprimen para reducir la virulencia del microorganismo es ESAT-6 (por early secretory antigenic target). Este gen codifica la producción de una proteína secretada cuya función aún se desconoce pero que estimula una intensa respuesta inmunitaria de tipo celular. De hecho, la ausencia de esta proteína de la vacuna BCG ha permitido que este antígeno se use para distinguir entre la presencia de infección por $M$. tuberculosis y el efecto de la vacunación con la BCG. Asimismo, la respuesta inmunitaria que desencadena la proteína ESAT-6 es indicio de protección contra la tuberculosis. Esto implica que la presencia de la proteína es un marcador de enfermedad así como de inmunidad. Otra proteína secretada que se asocia con la virulencia y que no está presente en la BCG es la llamada CFP-10 (por culture filtrate protein).

Un grupo de investigadores encabezado por Alexander Pym del Instituto Pasteur en París, Francia, se propuso mejorar la inmunogenia y capacidad protectora de dos vacunas a base de $M$. tuberculosis atenuado que se usan en la actualidad. Para lograrlo, jugaron con diferentes constructos dotados de los genes (es $x A$ y es $x B$, respectivamente) que codifican la ESAT-6 y la CFP-10 más algunos de los genes que los rodean. Solamente cuando reinsertaron todo el locus suprimido, que se compone de un mínimo de 11 genes, lograron conseguir la secreción completa de los dos antígenos y la consiguiente respuesta inmunitaria a ESAT-6 sin un aumento de la patogenia. Otro hallazgo importante del estudio es que la secreción de ESAT-6 (y quizá de CFP-10) es esencial para lograr una respuesta inmunitaria celular de máxima intensidad, si bien otras proteínas codificadas por genes del locus RD-1 contribuyen en menor medida. A partir de estos resultados cabe concluir que los genes que circundan a es $x A$ y es $x B$ codifican el aparato secretor de $M$. tuberculosis y que la reinserción del locus RD-1 entero mejora la eficacia de la vacuna y debe practicarse en toda vacuna nueva obtenida por recombinación génica, aunque sea necesario conseguir la atenuación del bacilo por medio de una mutación compensatoria. Es preciso advertir, sin embargo, que las vacunas recombinantes estudiadas confirieron mayor protección contra la infección del bazo que contra la del pulmón cuando se compararon con la BCG. (Pym AS et al. Recombinant BCG exporting ESAT-6 confers enhanced protection against tuberculosis. Nature Med 2003. Publicado el 14 de abril de 2003 en www. nature.com/nm/aop/.) 